\title{
Physical Activity, Sedentary Time, and Fatness in a Biethnic Sample of Young Children
}

\author{
PAUL J. COLLINGS ${ }^{1}$, SOREN BRAGE ${ }^{2}$, DANIEL D. BINGHAM ${ }^{1,3}$, SILVIA COSTA $^{4}$, JANE WEST $^{1}$, \\ ROSEMARY R. C. MCEACHAN ${ }^{1}$, JOHN WRIGHT ${ }^{1}$, and SALLY E. BARBER ${ }^{1}$ \\ ${ }^{1}$ Bradford Institute for Health Research, Bradford NHS Foundation Trust, Bradford, UNITED KINGDOM; ${ }^{2}$ MRC Epidemiology \\ Unit, University of Cambridge, Cambridge, UNITED KINGDOM; ${ }^{3}$ School of Sport, Exercise and Health Sciences, Loughborough \\ University, Leicestershire, UNITED KINGDOM; and ${ }^{4}$ UKCRC Centre for Diet and Activity Research (CEDAR), School of Clinical \\ Medicine, University of Cambridge, Cambridge, UNITED KINGDOM
}

\begin{abstract}
COLLINGS, P. J., S. BRAGE, D. D. BINGHAM, S. COSTA, J. WEST, R. R. MCEACHAN, J. WRIGHT, and S. E. BARBER. Physical Activity, Sedentary Time, and Fatness in a Biethnic Sample of Young Children. Med. Sci. Sports Exerc., Vol. 49, No. 5, pp. 930-938, 2017. Purpose: This study aimed to investigate associations of objectively measured physical activity (PA) and sedentary time with adiposity in a predominantly biethnic (South Asian and White British) sample of young children. Methods: The sample included 333 children age 11 months to $5 \mathrm{yr}$ who provided 526 cross-sectional observations for PA and body composition. Total PA volume (vector magnitude counts per minute), daily time at multiple intensity levels (the cumulative time in activity $>500,>1000,>1500, \ldots$, $>6000$ counts per minute), and time spent sedentary ( $<820$ counts per minute), in light PA (820-3907 counts per minute) and in moderate-to-vigorous PA ( $\geq 3908$ counts per minute) were estimated with triaxial accelerometry. Indicators of adiposity included body mass index, waist circumference, and the sum of subscapular and triceps skinfold thicknesses. Statistical analyses were performed using multilevel regression and isotemporal substitution models adjusted for confounders. Effect modification by ethnicity was examined. Results: There was no evidence for effect modification by ethnicity $(P$ interaction $\geq 0.13)$. In the whole sample, the accumulated time spent above 3500 counts per minute (i.e., high light-intensity PA) was inversely associated with the sum of skinfolds $\left(\beta=-0.60 \mathrm{~mm}, 95 \%\right.$ confidence interval $[\mathrm{CI}]=-1.19$ to -0.021 , per $\left.20 \mathrm{~min} \cdot \mathrm{d}^{-1}\right)$, and the magnitude of association increased dose dependently with PA intensity (peaking for time spent $>6000$ counts per minute $=-1.57 \mathrm{~mm}, 95 \% \mathrm{CI}=-3.01$ to -0.12 , per $20 \mathrm{~min} \cdot \mathrm{d}^{-1}$ ). The substitution of $20 \mathrm{~min} \cdot \mathrm{d}^{-1}$ of sedentary time with moderate-to-vigorous PA was associated with a lower sum of skinfolds $(-0.77 \mathrm{~mm}, 95 \% \mathrm{CI}=-1.46$ to -0.084$)$. Conclusions: High light-intensity PA appears to be beneficial for body composition in young South Asian and White British children, but higher-intensity PA is more advantageous. Key Words: EXERCISE, SEDENTARINESS, MOVEMENT, OBESITY, GROWTH, PEDIATRICS
\end{abstract}

\begin{abstract}
Address for correspondence: Paul J. Collings, Ph.D. (Cantab), Bradford Institute for Health Research, Bradford Teaching Hospitals NHS Foundation Trust, Bradford Royal Infirmary, Duckworth Lane, Bradford, BD9 6RJ, United Kingdom; E-mail: paul.collings@bthft.nhs.uk.

Submitted for publication July 2016.

Accepted for publication November 2016.

Supplemental digital content is available for this article. Direct URL citations appear in the printed text and are provided in the HTML and PDF versions of this article on the journal's Web site (www.acsm-msse.org).

\section{5-9131/17/4905-0930/0}

MEDICINE \& SCIENCE IN SPORTS \& EXERCISE $_{\circledast}$

Copyright $@ 2017$ The Author(s). Published by Wolters Kluwer Health, Inc. on behalf of the American College of Sports Medicine. This is an openaccess article distributed under the terms of the Creative Commons Attribution-Non Commercial-No Derivatives License 4.0 (CCBY-NC-ND), where it is permissible to download and share the work provided it is properly cited. The work cannot be changed in any way or used commercially without permission from the journal.
\end{abstract}

DOI: 10.1249/MSS.0000000000001180
$\mathrm{R}$ ecent reviews have emphasized that early childhood is a critical period for physical activity (PA) promotion and obesity prevention $(20,36)$. However, it is acknowledged that the amount and type of PA that is needed for healthy growth and development remains unclear. Part of this uncertainty stems from challenges in measuring young children's habitual PA, which is characterized by unplanned and unsustained bursts of movement that are unreliably recalled by young children with developing cognition, and which are nonconducive to accurate parent reports (27).

A small evidence base has emerged that has utilized accelerometry to estimate habitual PA and sedentary time (ST) in young children, with cross-sectional findings consistently supporting the notion that objectively measured high-intensity PA is inversely associated with adiposity (17). However, the studies performed to date vary in quality and scope. For instance, most have failed to explore the breadth of intensity data provided by accelerometry, instead favoring to concentrate exclusively on associations 
for moderate-to-vigorous PA (MVPA) in what has been termed "paradigm paralysis" (26). Investigating the entire spectrum of PA may help to elucidate patterns of association and will help to ascertain if underresearched components, such as light PA, be it at the low or high end of the light-intensity domain (8), are related to body composition. This is of particular importance in this age-group because much of young children's daily activity is performed within the light-intensity region (23), and although the merits of light PA remain largely unknown, national guidelines recommend that children younger than $5 \mathrm{yr}$ participate in $180 \mathrm{~min} \cdot \mathrm{d}^{-1}$ of PA at any intensity $(15,16,37)$.

Investigating the effects of displacing one intensity of PA for equal time in another or for ST (isotemporal substitution analysis) is also a novel methodological approach that has only once been implemented in young children (29). That study however, like most others that have incorporated traditional approaches $(10,25,38)$, was uniform with regard to ethnicity, being conducted in young White children with low prevalence of overweight and obesity and highly educated parents, thus limiting generalizability. For these reasons, despite some evidence for effect modification by ethnicity in primary school-age children $(21,39)$, accompanied by reports that South Asian children are less active and possess higher risk of obesity and related comorbidities (33), it remains unknown if PA and ST are differently associated with adiposity in South Asian and White British young children.

The aim of this investigation was to examine crosssectional associations of objectively measured PA volume and intensity distribution, and ST, with adiposity in a predominantly biethnic sample of young South Asian and White British children from a deprived city in the north of England.

\section{SUBJECTS AND METHODS}

\section{Description of study population}

Participants were recruited from a range of studies related to the Born in Bradford (BiB) birth cohort study (40) and research program (www.borninbradford.nhs.uk). This included the Healthy and Active Parenting Programme for early Years (HAPPY) feasibility randomized controlled trial (RCT) (30), the BiB-1000 observational cohort study (13), the Preschoolers in the Playground pilot cluster RCT (1), and the Learning Environment and Active Play (LEAP) observational study. Recruitment rates for each of the individual studies ranged from $31 \%$ to $48 \%$. Because overall intervention attendances were low in both pilot feasibility RCTs $(1,30)$ and there was no evidence for interaction by trial arm in the proceeding multivariate analyses (all $P$ interaction $\geq$ 0.10 ), data from both RCTs were treated as cohort and were not analyzed by trial arm. All data (up to four repeated measurements) from the Preschoolers in the Playground study were used. Table 1 provides specific details of each of the studies, all of which were conducted in the city of Bradford, the sixth largest and one of most deprived and ethnically diverse metropolitan boroughs in England $(14,40)$.

From an overall total of 451 study participants, 333 children between 11 months and $5 \mathrm{yr}$ of age (contributing 526 activity records, hereafter called observations) were included in this complete-case analysis. Because of the selection criteria of two studies $(1,30)$, our sample was more deprived than the overall $\mathrm{BiB}$ cohort, but there were no differences in sex or ethnic composition, and no difference in the sum of triceps and subscapular skinfolds, compared with participants of the population-based BiB-1000 study ( $P \geq 0.21$ for all; BiB-1000 includes 1707 children considered representative of the city of Bradford [4]). All studies in this pooled analysis received

TABLE 1. Description of studies.

\begin{tabular}{|c|c|c|c|}
\hline Study & Design/Objective & Population & Measurements \\
\hline HAPPY & $\begin{array}{l}\text { Pilot feasibility RCT investigating obesity risk } \\
\text { reduction in infants born to overweight or } \\
\text { obese mothers by encouraging breast feeding, } \\
\text { healthy food choices, and PA antenatally and } \\
\text { postnatally by mother and child }\end{array}$ & $\begin{array}{l}85 \text { 1-yr-olds ( } n=39 \text { intervention); mothers were recruited } \\
\text { when attending routine hospital appointments in } \\
\text { pregnancy; only children that could stand and walk } \\
\text { unaided were included in the current analysis }\end{array}$ & $\begin{array}{l}7 \text { d awake-time accelerometry; height and weight; } \\
\text { measurements performed between July } 2013 \\
\text { and March } 2014\end{array}$ \\
\hline PiP & $\begin{array}{l}\text { A cluster RCT piloting a playground-based PA } \\
\text { intervention. Data were collected at baseline, } \\
\text { 10,30, and } 52 \text { wk }\end{array}$ & $\begin{array}{l}1641.5 \text { - to } 4 \text {-yr-olds recruited from } 10 \text { primary schools } \\
\quad \text { (five intervention schools, } n=83 \text { intervention children) }\end{array}$ & $\begin{array}{l}7 \text { d awake-time accelerometry; height, weight, and waist } \\
\text { circumference; measurements performed between } \\
\text { September } 2012 \text { and May } 2014\end{array}$ \\
\hline BiB-1000 & $\begin{array}{l}\text { An obesity etiology substudy embedded within } \\
\text { the observational BiB project }\end{array}$ & $\begin{array}{l}\text { A subsample of } 972-\text { to } 4 \text {-yr-olds participating in } \\
\text { BiB-1000; parents were initially recruited when } \\
\text { attending routine oral glucose tolerance tests in } \\
\text { pregnancy }\end{array}$ & $\begin{array}{l}7 \text { d awake-time accelerometry; height, weight, waist } \\
\text { circumference, triceps and subscapular skinfolds; } \\
\text { measurements performed between June } 2011 \text { and } \\
\text { July } 2012\end{array}$ \\
\hline LEAP & $\begin{array}{l}\text { An observational study comparing children's PA, } \\
\text { gross motor skills, and body composition } \\
\text { between playground settings }\end{array}$ & $\begin{array}{l}105 \text { 3- to } 5 \text {-yr-olds ( } 76 \% \text { South Asian) recruited } \\
\quad \text { from two primary schools }\end{array}$ & $\begin{array}{l}7 \mathrm{~d} \text { continuous ( } 24 \mathrm{~h} \text { ) accelerometry; parent-reported } \\
\text { sleep diaries; height, weight, waist circumference, } \\
\text { triceps and subscapular skinfolds; measurements } \\
\text { performed September to November } 2015 \\
\text { Intraobserver reliability } \\
\text { Waist circumference }(n=78): \text { TEM }=0.49 \mathrm{~cm} ; r=0.97 \\
\text { Triceps skinfolds }(n=26) \text { : TEM }=0.25 \mathrm{~mm} ; r=0.99 \\
\text { Subscapular skinfolds }(n=25): \text { TEM }=0.41 \mathrm{~mm} ; r=0.99 \\
\text { Interobserver reliability } \\
\text { Triceps skinfolds }(n=14): \text { TEM }=0.66 \mathrm{~mm} ; r=0.79 \\
\text { Subscapular skinfolds }(n=12): \text { TEM }=0.66 \mathrm{~mm} ; r=0.86\end{array}$ \\
\hline
\end{tabular}

$r$ values are Pearson product-moment correlation coefficients.

PiP, Preschoolers in the Playground; TEM, technical error of measurement. 
either National Research Ethics Service or institutional ethical approval. Parental written informed consent and child assent were obtained before measurements.

Exposure measurement: PA and ST. Movement data were collected in all studies at a sampling frequency of $60 \mathrm{~Hz}$, using the same batch of accelerometers (ActiGraph GT3X+; ActiGraph, Pensacola, FL), worn under or over clothing at the hip on an elasticated belt for six to eight consecutive days. Raw acceleration data files were processed using Actilife (v6.13, ActiGraph) in 15-s epochs. Monitor nonwear and daytime napping were inferred from continuous zero vertical activity counts $\geq 10 \mathrm{~min}$ and were removed (7); traces were further visually scanned for implausible data. Scans revealed that approximately $20 \%$ of children who were asked to wear monitors only during waking hours actually wore the monitor continuously for $24 \mathrm{~h}$, similar to the protocol used in the LEAP study (Table 1). To remove sleep from all acceleration records, a hierarchy of methods was used: 1) parent-reported sleep diary data were used to identify daily sleep onset and termination times; 2) in the absence of sleep diary data, daily plots of acceleration data were scrutinized, with the beginnings of persistent low movement registration in the evening considered a sign of sleep onset and movement initiation on mornings identified as sleep termination; and 3) if there was high-level movement after a parent-reported sleep onset, sleep timings from the acceleration data were prioritized. This multimethod approach to eliminating sleep from 24-h accelerometry resembles a method previously used (12), and all judgments were made by a single experienced reviewer who was entirely blinded to participant characteristics other than acceleration data and sleep diaries. In sensitivity analyses, the accelerometry data were also processed using an automated and objective method that has face validity for sleep identification (10).

All days with $\geq 6 \mathrm{~h}$ of data after removal of sleep were considered valid. To maximize power and mitigate selection biases, all children with $\geq 1$ valid day were included in this analysis. Sensitivity analyses were also performed that included only children with three or more valid days of data, an amount that has been shown to provide reliable activity estimates in the source population (3). These days were not required to include weekends, but as young children's movement behaviors appear to vary throughout a day (23), another sensitivity analysis was performed that imparted a time distribution caveat; here a valid day was required to possess $\geq 1 \mathrm{~h}$ of observed time in the morning (06:00-12:00), afternoon (12:00-17:00), and evening (17:00-23:00). For each definition of valid wear, the average daily vector magnitude counts per minute was calculated as an indicator of total PA volume, and the time distribution of PA intensity was generated by calculating the accumulated time $\left(\min \cdot \mathrm{d}^{-1}\right)$ above specific vector magnitude intervals (the total time in activity $>500,>1000,>1500, \ldots,>6000$ counts per minute). Data were further processed "classically" by using validated thresholds to estimate time spent sedentary $(<820$ vector magnitude counts per minute), in light PA (820-3907 counts per minute), and MVPA ( $\geq 3908$ counts per minute) (6). Adherence (defined as performing on average $\geq 180 \mathrm{~min}$ PA per day) to activity guidelines was also quantified $(15,16,37)$.

Outcome measurement: adiposity data. With the exceptions of length (measured by a rollameter in the HAPPY study) and weight (measured in BiB-1000 by Tanita scales, BC-418MA, Tokyo, Japan), all studies measured height (Holtain Ltd., UK) and weight (Seca 877, UK) with the same calibrated equipment used by the same trained personnel. The data were used to calculate body mass index (BMI, $\mathrm{kg} \cdot \mathrm{m}^{-2}$ ), which was converted to $z$-scores and weight status categories for description (9). Waist circumferences were measured with Seca anthropometrical tape at the level of the exposed naval, in duplicate or triplicate if the first two measures differed by $\geq 3 \mathrm{~cm}$; all data were used to calculate means. The BiB-1000 and the LEAP studies included single measurements of triceps and subscapular skinfolds on the left side of the body using standard procedures (Tanner/ Whitehouse Calipers; Holtain Ltd., UK). Random subsamples of LEAP study participants also underwent repeated skinfold measurements to permit calculation of intra- and interobserver technical error of measurement for waist circumference, triceps, and subscapular skinfolds (Table 1); relative technical error of measurement values were acceptable and indicative of "skilful" anthropometrists (34).

Covariables. Parent reports or school records were used to provide participant age, sex, home postcode, and ethnicity. Children of unmixed ethnic origin were classified as either South Asian (including Pakistani, Bangladeshi, or "other" South Asian origin) or White British, whereas children of "other" or mixed ethnicity were allocated to a separate category. Home postcodes were used alongside the English index of multiple deprivation to create deciles of area-level deprivation (which were grouped into the lowest $10 \%, 10 \%-30 \%$, and $\geq 30 \%$ ) (14). Time-stamped information from accelerometers identified the season of measurements (winter, December to February; spring, March to May; summer, June to August; autumn, September to November), and wear time was captured.

Statistical analysis. Descriptive characteristics were summarized using means with SD (all variables were approximately normally distributed) or frequencies. Comparisons between South Asian and White British children were made using linear (continuous variables) or logistic (categorical variables) multilevel regression; the mixed ethnic group was too small for comparison. A multivariate test of means was used to investigate differences between South Asian and White British children in regard to the cumulative awake time spent above vector magnitude intervals. Pearson productmoment correlation coefficients quantified relations between PA and ST variables as well as between adiposity indicators.

Associations between components of PA and ST (exposures) with adiposity indicators (outcomes; all modeled continuously) were estimated by linear multilevel regression analysis. Multilevel models were used to account for repeatedmeasures data (level 1) nested within children (level 2) 
clustered within schools (level 3; HAPPY and BiB-1000 children were not recruited from schools and were assigned a dummy variable). Crude models were initially performed followed by adjustment for age, sex, ethnicity, index of multiple deprivation, monitor wear time (not in models with total PA volume as the exposure), and season of assessment. When waist circumference and sum of skinfolds were outcomes, additional adjustment for height was made. Models were specified with random intercepts at child level but not random slopes as they explained little to no variation in outcomes.

The previously described models were first used to investigate associations of the cumulative time above specific vector magnitude intervals (time in activity $>500,>1000$, $>1500, \ldots,>6000$ counts per minute; each intensity occupied a single model) with outcomes. Models were then used to investigate associations of the classic PA and ST categories, and total PA volume, with the same outcomes. In this second analysis, two primary models were constructed: model 1 was adjusted for all aforementioned factors and model 2 (not applicable to total PA volume) was built in the same manner but entailed mutual adjustment for each of the PA intensities by simultaneously including light PA and MVPA categories in the linear predictor. As this model was constrained to invariant time by adjusting for monitor wear time and leaving out only ST, the results represent isotemporal substitution, in other words the effect on the outcome of exchanging a unit of ST for PA (inverting the results is the effect of exchanging a unit of PA for ST) (31). To cover all isotemporal eventualities, the omitted category was subsequently changed from ST to light PA and models were rerun.

In all analyses, nonlinear variation was examined by introducing quadratic terms for exposures, and interactions by ethnicity were explored (effect modification by ethnicity was limited to a comparison of associations between South Asian and White British children because of the diminutive mixed ethnic group). All results are presented per $20 \mathrm{~min} \cdot \mathrm{d}^{-1}$ for time-based exposures and 300 counts per minute for total PA volume, which are approximate SD values of the activity data or multiples thereof. Statistical analyses were conducted in Stata/SE 13.1 (StataCorp, College Station, TX). $P$ values $<0.05$ were deemed statistically significant.

\section{RESULTS}

A total of 333 children ( $50.7 \%$ boys $)$ with a mean age of $3.3 \pm 0.9$ yr were included in the analysis, of whom $37 \%$ were of White British and 55\% were of South Asian origin (Table 2); the South Asian group was predominantly Pakistani origin (74\%). Overall, $20 \%$ of children were overweight or obese, and South Asian children were from more deprived areas and exhibited lower BMI compared with White British children (Tables 2 and 3). Although most children (67\%) possessed valid accelerometry and anthropometry at only one time point, repeated measures were available for 110 children who provided data on two $(12 \%)$, three $(17 \%)$, or four $(4 \%)$ occasions. The number of valid observations totaled 526 (the unit of analysis in this investigation), which were spread across all seasons (winter, 15\%; spring, 26\%; summer, 23\%; autumn, 36\%). Observations were informed by 1-2 (15\%), 3-5 $(28 \%)$, or $\geq 6(57 \%)$ valid days of accelerometry, and the mean monitor wear time was $575.6 \pm 93.0 \mathrm{~min} \cdot \mathrm{d}^{-1}$. There were no differences in time spent in any PA or ST category between South Asian and White British children (Table 3) and no difference in adherence to PA guidelines $(P=0.14) ; 95 \%$ of all activity observations were characterized by $\geq 180 \mathrm{~min}$ PA per day. Figure 1 illustrates the cumulative awake time above discreet vector magnitude thresholds. In every ethnic group, an exponential decline as a function of increasing PA intensity was observed; again there was no difference in means between South Asian and White British children $(P=0.76)$. Pearson's correlation analysis showed that the strongest correlation for time-based exposures was between ST and light PA $(r=-0.65)$, and that BMI was more strongly correlated with waist circumference $(r=0.76)$ than the sum of skinfolds $(r=0.61)$, which were also themselves correlated $(r=0.70$ between waist circumference and sum of skinfolds; $P<0.001$ for all).

There was no evidence for interaction by ethnicity in any of the main analyses $(P \geq 0.13)$, and hence results for all models are presented for the total sample adjusted for ethnicity. Figure 2 shows associations between the cumulative time above increasing vector magnitude intensity thresholds with adiposity indicators. There were no significant associations for BMI (Fig. 2A) or waist circumference (Fig. 2B), but time

TABLE 2. Characteristics of study participants: categorical variables.

\begin{tabular}{|c|c|c|c|c|c|}
\hline Characteristic & Total $(N=333)$ & Other/Mixed $(n=27)$ & South Asian $(n=184)$ & White British $(n=122)$ & P Ethnicity, South Asian vs White British \\
\hline \multicolumn{6}{|l|}{ Gender, $n(\%)$} \\
\hline Boys & $169(50.8)$ & $14(51.9)$ & $88(47.8)$ & $67(54.9)$ & \\
\hline Girls & 164 (49.2) & $13(48.1)$ & $96(52.2)$ & $55(45.1)$ & 0.23 \\
\hline \multicolumn{6}{|l|}{$\mathrm{IMD}^{\mathrm{a}}$} \\
\hline Most deprived $10 \%$ & $200(60.1)$ & $15(55.6)$ & $135(73.4)$ & $50(41.0)$ & \\
\hline $10 \%-30 \%$ & $88(26.4)$ & $11(40.7)$ & 39 (21.2) & $38(31.1)$ & \\
\hline$\geq 30 \%$ & 45 (13.5) & $1(3.7)^{\prime}$ & $10(5.4)^{\prime}$ & $34(27.9)$ & 0.003 \\
\hline \multicolumn{6}{|l|}{ Weight status $^{b}$} \\
\hline Normal & $268(80.5)$ & $21(77.8)$ & $150(81.5)$ & $97(79.5)$ & \\
\hline Overweight & $31(9.3)$ & $5(18.5)$ & $14(7.6)$ & $12(9.8)$ & \\
\hline Obese & $34(10.2)$ & $1(3.7)$ & $20(10.9)$ & $13(10.7)$ & 0.71 \\
\hline
\end{tabular}

Ethnic group comparisons were performed using multilevel logistic regression for gender and multilevel ordered logistic regression for IMD and weight status; multilevel models were used to account for school clustering. IMD, index of multiple deprivation.

${ }^{a}$ Based on the national measure of relative deprivation for small areas in England.

${ }^{b}$ Based on British growth reference data and using only the earliest available time point from the Preschoolers in the Playground study. 
TABLE 3. Characteristics of study participants: continuous variables.

\begin{tabular}{|c|c|c|c|c|c|}
\hline Characteristic & $\begin{array}{c}\text { Total }(N=333 ; \\
\text { Observations }=526)\end{array}$ & $\begin{array}{l}\text { Other/Mixed }(n=27 \text {; } \\
\text { Observations }=40)\end{array}$ & $\begin{array}{c}\text { South Asian }(n=184 ; \\
\text { Observations }=315)\end{array}$ & $\begin{array}{l}\text { White British }(n=122 \text {; } \\
\text { Observations = 171) }\end{array}$ & $\begin{array}{l}P \text { Ethnicity, South Asian } \\
\text { vs White British }\end{array}$ \\
\hline Age (yr) & $3.3 \pm 0.9$ & $3.0 \pm 1.2$ & $3.4 \pm 1.0$ & $3.2 \pm 0.8$ & 0.76 \\
\hline Height $(\mathrm{cm})$ & $96.8 \pm 8.6$ & $93.7 \pm 10.1$ & $98.1 \pm 8.6$ & $95.1 \pm 7.6$ & 0.068 \\
\hline Weight (kg) & $15.3 \pm 3.0$ & $14.6 \pm 3.7$ & $15.5 \pm 3.2$ & $15.0 \pm 2.4$ & 0.83 \\
\hline BMI $\left(\mathrm{kg} \cdot \mathrm{m}^{-2}\right)$ & $16.2 \pm 1.7$ & $16.3 \pm 1.5$ & $16.0 \pm 1.8$ & $16.6 \pm 1.5$ & 0.004 \\
\hline BMI $z$-score ${ }^{a}$ & $0.058 \pm 1.2$ & $0.089 \pm 1.1$ & $-0.11 \pm 1.3$ & $0.36 \pm 1.0$ & 0.004 \\
\hline Waist circumference $(\mathrm{cm})^{b}$ & $50.5 \pm 4.5$ & $49.4 \pm 3.5$ & $50.6 \pm 5.1$ & $50.8 \pm 3.5$ & 0.84 \\
\hline ST $\left(\min \cdot d^{-1}\right)$ & $282.3 \pm 64.6$ & $298.1 \pm 70.9$ & $280.1 \pm 66.5$ & $282.5 \pm 59.2$ & 0.108 \\
\hline Light PA $\left(\min \cdot d^{-1}\right)$ & $242.0 \pm 54.0$ & $232.9 \pm 47.9$ & $244.2 \pm 55.3$ & $239.9 \pm 52.8$ & 0.12 \\
\hline MVPA $\left(\min \cdot d^{-1}\right)$ & $51.4 \pm 23.5$ & $47.1 \pm 25.6$ & $52.5 \pm 24.2$ & $50.3 \pm 21.5$ & 0.080 \\
\hline Vector magnitude (counts per minute) & $1371.2 \pm 320.2$ & $1278.3 \pm 358.4$ & $1389.1 \pm 323.5$ & $1359.9 \pm 301.6$ & 0.25 \\
\hline Monitor wear time $\left(\min \cdot d^{-1}\right)$ & $\begin{array}{r}575.6 \pm 93.0 \\
(n=156)\end{array}$ & $\begin{array}{c}578.1 \pm 72.9 \\
(n=12)\end{array}$ & $\begin{array}{c}576.8 \pm 97.8 \\
\quad(n=83)\end{array}$ & $\begin{array}{c}572.8 \pm 88.4 \\
(n=61)\end{array}$ & 0.006 \\
\hline Triceps skinfold (mm) & $10.1 \pm 2.6$ & $11.2 \pm 2.9$ & $10.4 \pm 2.7$ & $9.4 \pm 2.2$ & 0.094 \\
\hline Subscapular skinfold (mm) & $6.6 \pm 2.6$ & $7.7 \pm 4.0$ & $7.0 \pm 2.9$ & $5.8 \pm 1.2$ & 0.58 \\
\hline Sum of skinfolds (mm) & $16.6 \pm 4.7$ & $18.8 \pm 6.2$ & $17.4 \pm 5.2$ & $15.2 \pm 3.1$ & 0.47 \\
\hline
\end{tabular}

All variables were approximately normally distributed, and all values are presented as mean \pm SD. Ethnic group comparisons were performed using multilevel linear regression to account for school clustering and (excluding skinfold comparisons) repeated measures. There were no differences in $P$ values if comparisons were adjusted for index of multiple deprivation. ${ }^{a}$ Based on British growth reference data.

${ }^{b}$ Data available for 310 participants who provided 457 observations.

spent above 3500 counts per minute (i.e., high lightintensity PA to adopt terminology used by others [8]) was inversely associated with skinfold thickness, with every $20 \mathrm{~min} \cdot \mathrm{d}^{-1}$ related to $0.60 \mathrm{~mm}$ lower sum of skinfolds (Fig. 2C; $P=0.042$ ). This relationship was characterized by a dose-dependent graded association, as the magnitude of association strengthened with increasing activity intensity, such that every $20 \mathrm{~min} \cdot \mathrm{d}^{-1}$ spent above 6000 counts per minute was associated with $1.57 \mathrm{~mm}$ lower sum of skinfolds $(P=0.034)$. These dose-dependent results were largely consistent with categorical analyses (Table 4), which showed a significant inverse association between MVPA and the sum of skinfolds, and revealed that replacing $20 \mathrm{~min} \cdot \mathrm{d}^{-1}$ of ST with MVPA was associated with $0.77 \mathrm{~mm}$ lower sum of skinfolds. Shifting the same amount of time from the light PA category to MVPA had a similar effect, tending toward significance $(P=0.068)$.
All of the results were materially similar and conclusions remained unchanged when analyses were performed with accelerometer data that were diurnally well balanced and derived from automated exclusion of sleep. The same applies to analyses that only included children with $\geq 3 \mathrm{~d}$ of accelerometry and models that were rerun with exclusion of intervention (nonbaseline) data, the results of which are presented as supplementary material (see Table, Supplemental Digital Content 1, Associations of categories for ST and PA with adiposity indicators (exclusive of all nonbaseline intervention data), http://links.lww.com/MSS/A838).

\section{DISCUSSION}

This is the first study to comprehensively investigate the relations between PA, ST, and adiposity in a predominantly biethnic group of young children. Our results contribute to a

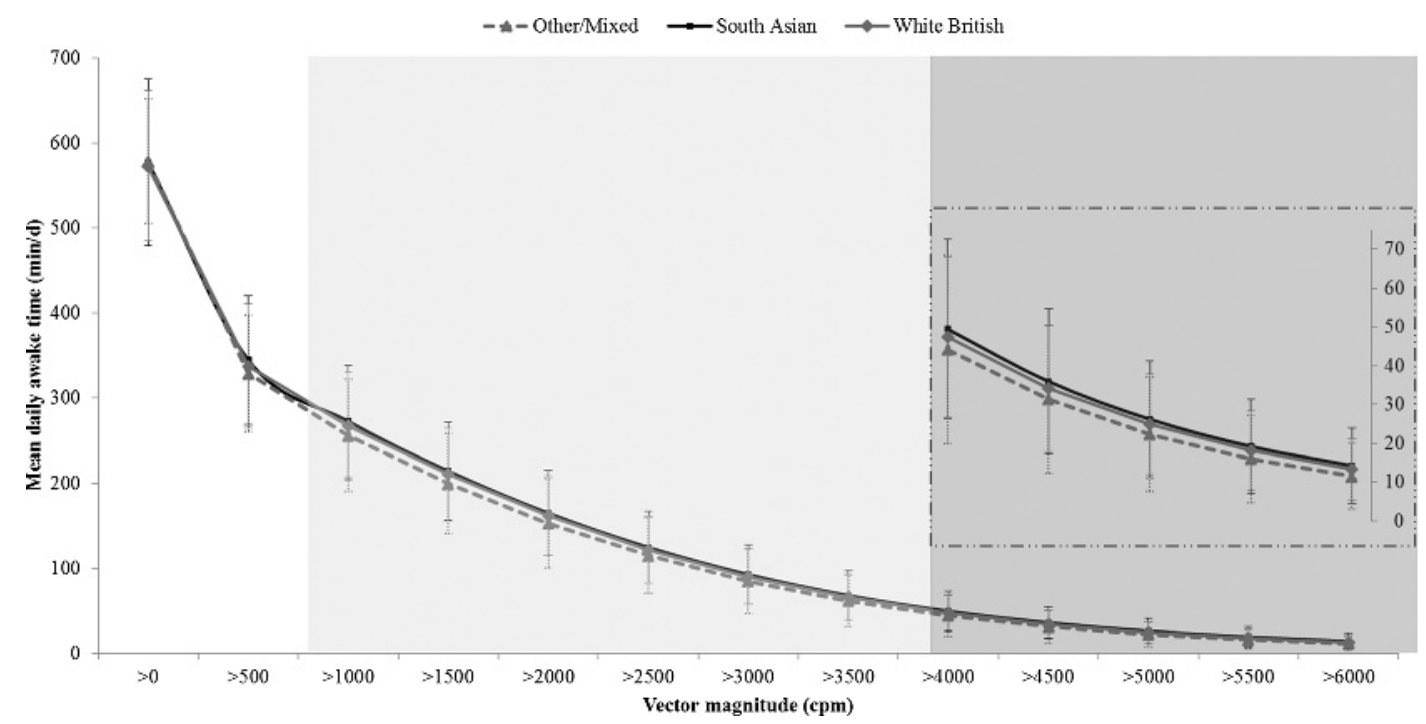

FIGURE 1-Daily cumulative awake time spent above vector magnitude intervals. Data are mean values, and error bars represent \pm SD. Light PA (820-3908 counts per minute) corresponds to the light shaded region and MVPA ( $\geq 3908$ counts per minute) to the dark shaded region. The inset shows a magnified plot for $>\mathbf{4 0 0 0}$ counts per minute. A multivariate test of means provided no evidence for a difference between South Asian and White British $(P=0.76)$. CPM, counts per minute. 

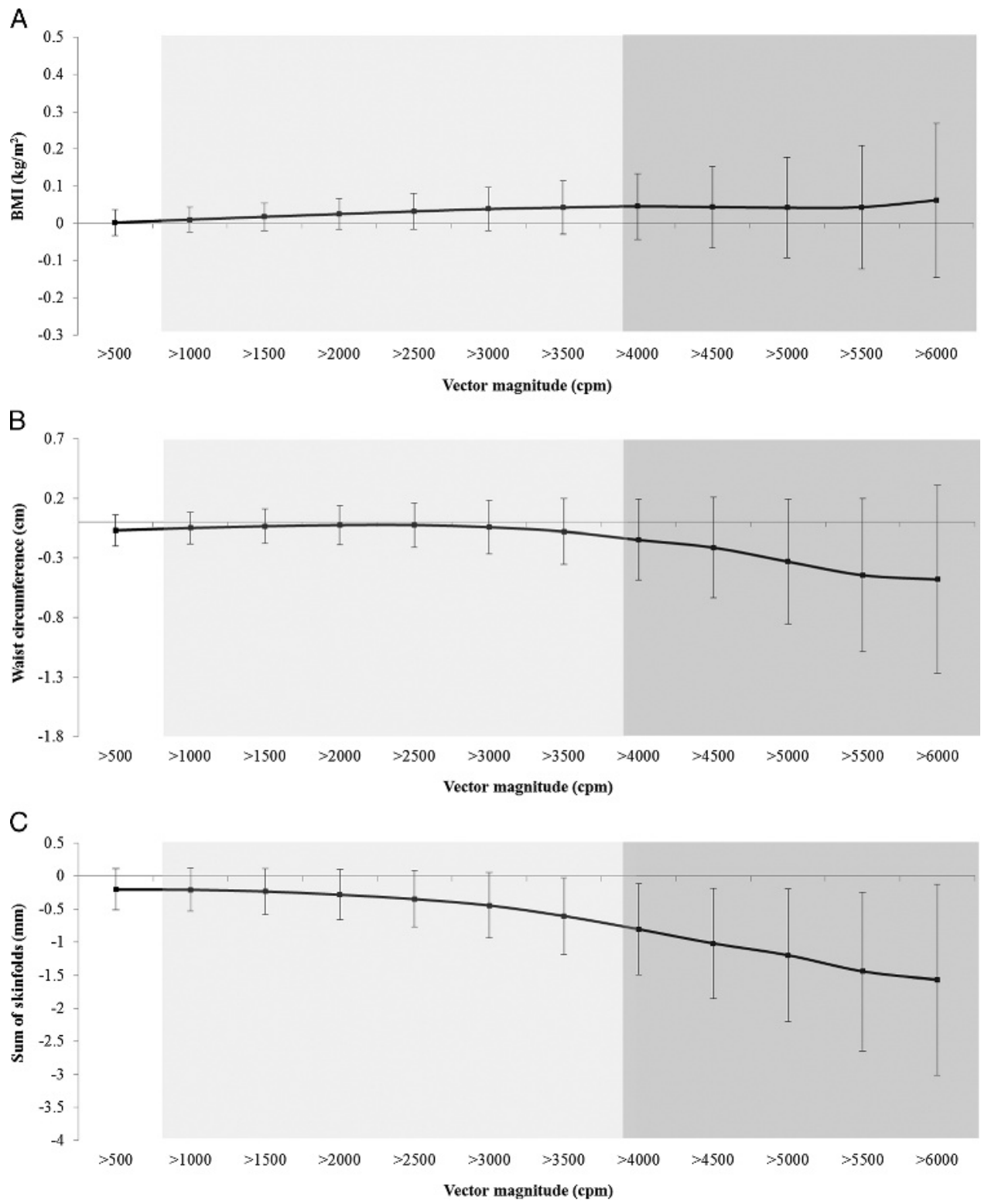

FIGURE 2-Associations between the cumulative awake time above vector magnitude intervals with BMI (A), waist circumference (B), and sum of skinfolds (C). Statistical analyses performed using multilevel models adjusted for age, sex, ethnicity, index of multiple deprivation, monitor worn time, and season of assessment. Models for waist circumference $(n=310$; observations $=457)$ and the sum of skinfolds $(n=156 ;$ observations $=156)$ were further adjusted for height. BMI: $n=333$; observations = 526. All results are beta-coefficients with $95 \%$ confidence intervals and are scaled to represent the association between exposures and outcomes per 20-min difference in exposures. Light PA (820-3908 counts per minute) corresponds to the light shaded region and MVPA ( $\geq 3908$ counts per minute) to the dark shaded region. CPM, counts per minute.

growing body of evidence for inverse cross-sectional associations between MVPA and measures of adiposity in children aged 5 yr and younger $(5,10,25,29,32,38)$. However, our investigation provides new and unique evidence; by investigating the entire spectrum of activity intensities, we found a dose dependency between PA and adiposity, which first appeared below the threshold for MVPA in both South Asian and White British children.

A particular strength of this study was the use of triaxial accelerometry and short sampling intervals to account for the diverse and erratic movement patterns of young children. We identified that regardless of ethnicity, the waking day was dominated by ST (accounting for $49 \%$ of the average $9.6 \mathrm{~h}$ daily wear time) and light PA ( $42 \%$ of wear time), with relatively little time spent in MVPA ( $9 \%$ of wear time). These estimates closely match those from Butte et al. (5) who provide the only closely comparable data by using the same cut points. Despite considerable engagement in light activity (particularly at the low end of the light-intensity spectrum as shown in Fig. 1), we found little evidence for associations between our light PA category and measures of healthier body composition, which is in line with the few existing data in this age-group $(10,29,32)$. A key limitation of all studies, nonetheless, has been a reliance on purely 
TABLE 4. Associations of categories for ST and PA with adiposity indicators

\begin{tabular}{|c|c|c|c|c|c|c|}
\hline & \multicolumn{2}{|c|}{$\begin{array}{c}\text { BMI }\left(\mathrm{kg} \cdot \mathrm{m}^{-2}\right) \\
(N=333 ; \text { Observations }=526)\end{array}$} & \multicolumn{2}{|c|}{$\begin{array}{c}\text { Waist Circumference }(\mathrm{cm}) \\
(n=310 ; \text { Observations }=457)\end{array}$} & \multicolumn{2}{|c|}{$\begin{array}{c}\text { Sum of Skinfolds }(\mathrm{mm}) \\
(n=156 ; \text { Observations }=156)\end{array}$} \\
\hline & $\beta(95 \%$ CI) & $P$ & $\beta(95 \% \mathrm{CI})$ & $P$ & $\beta(95 \% \mathrm{CI})$ & $P$ \\
\hline \multicolumn{7}{|l|}{ Model 1} \\
\hline ST & $-0.0069(-0.040$ to 0.027$)$ & 0.69 & $0.056(-0.075$ to 0.19$)$ & 0.40 & $0.21(-0.12$ to 0.53$)$ & 0.21 \\
\hline Light PA & $-0.00021(-0.043$ to 0.042$)$ & 0.99 & $-0.056(-0.22$ to 0.11$)$ & 0.51 & $-0.059(-0.47$ to 0.35$)$ & 0.78 \\
\hline MVPA & $0.045(-0.040$ to 0.13$)$ & 0.30 & $-0.14(-0.46$ to 0.19$)$ & 0.41 & $-0.76(-1.43$ to -0.085$)$ & 0.027 \\
\hline Total PA (counts per minute) & $0.042(-0.037$ to 0.12$)$ & 0.30 & $-0.072(-0.39$ to 0.24$)$ & 0.65 & $-0.64(-1.46$ to 0.19$)$ & 0.13 \\
\hline \multicolumn{7}{|l|}{ Model 2-isotemporal substitution } \\
\hline ST $\rightarrow$ Light PA & $-0.0096(-0.055$ to 0.036$)$ & 0.68 & $-0.034(-0.21$ to 0.15$)$ & 0.71 & $0.048(-0.37$ to 0.47$)$ & 0.82 \\
\hline ST $\rightarrow$ MVPA & $0.052(-0.039$ to 0.14$)$ & 0.27 & $-0.11(-0.46$ to 0.24$)$ & 0.54 & $-0.77(-1.46$ to -0.084$)$ & 0.028 \\
\hline Light PA $\rightarrow$ MVPA & $0.061(-0.054$ to 0.18$)$ & 0.30 & $-0.077(-0.53$ to 0.37$)$ & 0.74 & $-0.82(-1.71$ to 0.062$)$ & 0.068 \\
\hline
\end{tabular}

Statistical analyses performed using multilevel models adjusted for age, gender, ethnicity, index of multiple deprivation, monitor wear time (not in models with total PA as the outcome), and season of assessment. Models with waist circumference and sum of skinfolds as the outcomes were further adjusted for height. All results are scaled to represent the association between exposures and outcomes per 20-min difference in time-based exposures and 300 total PA counts per minute. Model 2 shows isotemporal substitution results and the effect of exchanging 20 min of ST or PA for different PA intensities. For example, shifting 20 min of ST to MVPA was associated with 0.77 mm lower sum of skinfolds, and vice versa shifting $20 \mathrm{~min}$ of MVPA to ST was associated with $0.77 \mathrm{~mm}$ higher sum of skinfolds. Statistically significant results are in bold. Cl, confidence interval.

accelerometer-based (and often only uniaxial) measures. The capability of such devices to accurately register what may be a more diverse and varied movement profile at the lowest end of the intensity spectrum (most MVPA even in young children is walking or running [19,24]), coupled with misclassification errors between ST and light PA (behaviors that are hypothesized to be oppositely related with adiposity), might provide two explanations why most studies have found little evidence of an association for light PA, particularly when that typically represents the full light-intensity range. Recently in adolescents, the light-intensity continuum has been divided into low (e.g., standing) and high lightintensity PA (e.g., slow walking) categories, and high lightintensity was found to be more favourably associated with cardiometabolic risk (8). Similarly, our novel cumulative analysis of intensity distributions revealed an inverse association between light PA and adiposity, but only at the high end of the light-intensity continuum ( $>3500$ counts per minute); for every $20 \mathrm{~min} \cdot \mathrm{d}^{-1}$ of PA exceeding this intensity, the sum of skinfolds was lower by $0.60 \mathrm{~mm}$. This observation is in partial agreement with at least two studies in older children, which have reported inverse associations between light PA as a whole and adiposity $(11,28)$. Notably, one of those studies incorporated uninterrupted $(24 \mathrm{~h})$ combined heart rate and movement sensing to better characterize ST and all categories of PA (including light activity), which may explain the novel findings. Like the results reported herein, that study also found an inverse dose-dependent association between intensity distribution and adiposity, starting in the lightintensity region (11).

Although we witnessed some indication of an inverse trend between higher-intensity PA and waist circumference (Fig. 2B), we only found significant results for the sum of skinfolds. Other studies have similarly found null associations between PA and adiposity as defined by BMI or waist circumference, but inverse associations using more direct measures of adiposity $(18,29)$. Our findings support the notion that BMI and the sum of skinfolds provide different measures of adiposity (18) and that height-for-weight indices and circumferences may be suboptimal indicators of body fatness in children (2). Our observation that for every
$20 \mathrm{~min} \cdot \mathrm{d}^{-1}$ of MVPA the sum of skinfolds was lower by $0.76 \mathrm{~mm}$ may seem modest in scale, but the average MVPA exceeded $50 \mathrm{~min} \cdot \mathrm{d}^{-1}$ and measurement error may have attenuated the association. Furthermore, previous studies in young children have reported that inverse associations with laboratory-measured adiposity are only apparent $(10,25)$ or are strongest (29) for vigorous PA. Our cumulative analysis of intensity supports the idea that PA is related to adiposity dose dependently in early childhood, and that time-for-time higher-intensity PA is most strongly related to adiposity (11): $20 \mathrm{~min} \cdot \mathrm{d}^{-1}$ of PA exceeding an intensity of 6000 counts per minute was associated with $1.57 \mathrm{~mm}$ lower sum of skinfolds. We found no evidence for associations between total PA and adiposity, which might suggest that our observed associations for higher-intensity PA were not driven by total activity volume. While it is biologically plausible that vigorous activity may be important for adiposity over and above activity volume (for reasons related to appetite regulation and increased postactivity energy expenditure), whether or not young children's sporadic and unsustained habitual PA can stimulate such pathways remains to be determined (10).

Our findings partially support current activity guidelines for young children, which endorse minimal ST and $180 \mathrm{~min}$ PA per day of any intensity $(15,16,37)$, as we did find a significant inverse association between light PA and adiposity albeit at the higher end of the light continuum. Studies in older children (some with improved exposure measurement [11]) have reported inverse associations between the full intensity range of light PA and adiposity $(11,28)$, and light activity could also be beneficial for child health independent of body fat status (8), as well as essential for motor skill acquisition which requires substantial active time. In this study, light PA accounted for $>80 \%$ of all active minutes, which is consistent with a study of preschoolers (23). Nevertheless, in the current sample although $95 \%$ of activity observations exceeded the recommended volume of PA per day (chiefly satisfied by engaging in low lightintensity PA as shown in Fig. 1), approximately $20 \%$ of children were still overweight or obese. Given this, coupled with our dose-dependent negative associations between PA 
intensity and adiposity, our data imply that guidelines might better acknowledge the merit of higher-intensity PA for lower adiposity. Higher-intensity PA has also been demonstrated to have wider benefit for fitness and improved cardiometabolic risk $(11,22,29)$. A subtle change in focus from exclusively PA volume would further appear reasonable in terms of preparing young children for the guideline change, when $60 \mathrm{~min}$ MVPA per day alongside an unspecified volume of vigorous PA (on at least $3 \mathrm{~d} \cdot \mathrm{wk}^{-1}$ ) is endorsed for $\geq 5$-yr-olds (15). Because we found no interaction by ethnicity, it appears that a recommendation for some higher-intensity PA performed in early childhood would be equally beneficial for the body composition of young South Asian and White British children. This is important in the context of health equality, and because South Asians are a high-risk group for obesity and cardiometabolic disease.

Strengths/limitations. Our study benefits from a welldescribed sample that is young, ethnically diverse, and from a deprived urban setting. This reflects a population at particularly high risk of childhood obesity and subsequent adverse health consequences. We harmonized data from four studies to achieve a relatively large sample size and capitalized on repeated measures for one-third of the cohort, thereby reducing the regression dilution effect. Habitual PA was also estimated objectively using triaxial accelerometry and a population-specific wear criterion (3). It is unfortunate that data for the sum of skinfolds were only available for a subsample of participants, but we advantageously retained all adiposity indicators in their continuous forms for analyses thereby raising statistical power and avoiding decisions regarding categorization. With regard to confounding, similar studies $(10,11,35)$ have found little evidence for a confounding influence by factors such as household income, maternal education, maternal obesity, smoking in pregnancy, and birth weight, which is reassuring as we could not account for them, but energy intake and diet patterns remain possible prominent confounders of our associations. It is also a weakness that the direction of association between variables, let alone causality, is indeterminable because of the cross-sectional study design. For instance, bidirectional associations may exist

\section{REFERENCES}

1. Barber SE, Jackson C, Hewitt C, et al. Assessing the feasibility of evaluating and delivering a physical activity intervention for preschool children: a pilot randomised controlled trial. Pilot Feasibility Stud. 2016;2(1):12.

2. Basterfield L, Pearce MS, Adamson AJ, Reilly JK, Parkinson KN, Reilly JJ. Effect of choice of outcome measure on studies of the etiology of obesity in children. Ann Epidemiol. 2012;22(12): 888-91.

3. Bingham DD, Costa S, Clemes SA, Routen AC, Moore HJ, Barber SE. Accelerometer data requirements for reliable estimation of habitual physical activity and sedentary time of children during the early years - a worked example following a stepped approach. J Sports Sci. 2016;34(20):2005-10.

4. Bryant M, Santorelli G, Fairley L, et al. Design and characteristics of a new birth cohort, to study the early origins and ethnic variation between exposures and outcomes, and thus our results may equally imply that less fat children have more favorable ST and PA profiles.

To conclude, this study found that for improved body composition in young children of different ethnicity, at least high light-intensity PA is necessary, but higher-intensity PA is more beneficial. Public health bodies might consider basing recommendations around the concept of dose-dependent relationships; by occasionally choosing MVPA over light PA and particularly ST, health benefits can be expected, and greater benefit may arise from higher doses.

The authors are grateful to all the schools, families, and children that took part in each of the studies and to the $\mathrm{BiB}$ community team for assisting with recruitment and data collection. The studies used in this research have been financially supported by the National Institute for Health Research (NIHR) program grant for applied research (RP-PG-0407-10044), the NIHR Public Health Research (PHR 11/3001/16), and the NIHR CLAHRC Yorkshire and the Humber. The views expressed are those of the authors and not necessarily those of the NHS, the NIHR, or the Department of Health. The results of the study are presented clearly, honestly, and without fabrication, falsification, or inappropriate data manipulation. The results of the present study do not constitute endorsement by the American College of Sports Medicine.

Paul Collings, Soren Brage, Daniel Bingham, Silvia Costa, Jane West, Rosemary McEachan, John Wright, and Sally Barber declare that they have no conflict of interest. All studies involved in this manuscript received either National Research Ethics Service or institutional ethical approval. Parental written informed consent and child assent were obtained before measurements.

Authors P. J. C., D. D. B., J. We., R. R. C. M., J. Wr., and S. E. B. are part of the Healthy Children, Healthy Families Theme of the NIHR CLAHRC Yorkshire and the Humber. Author S. B. is supported by the UK Medical Research Council (grant no. MC_UU_12015/3). None of the authors reported a conflict of interest related to the study.

The authors' responsibilities were as follows: P. J. C. designed and conducted the research, analyzed data, wrote the article, and had primary responsibility for the final content of the manuscript. S. B. assisted in the design of the statistical analysis and critiqued the manuscript. D. D. B. assisted in the processing of accelerometer data. D. D. B., S. C., J. We., R. R. C. M., J. Wr., and S. E. B. designed individual studies, organized and managed data collections, and critiqued the manuscript; all authors approved the final manuscript as submitted.

Clinical Trial Registry number and website: The HAPPY (ISRCTN56735429) and PiP (ISRCTN54165860) pilot randomized controlled trials are both registered with the ISRCTN (http://www.isrctn.com).

of childhood obesity: the BiB1000 study. Longit Life Course Stud. 2013;4(2):119-35.

5. Butte NF, Puyau MR, Wilson TA, et al. Role of physical activity and sleep duration in growth and body composition of preschoolaged children. Obesity (Silver Spring). 2016;24(6):1328-35.

6. Butte NF, Wong WW, Lee JS, Adolph AL, Puyau MR, Zakeri IF. Prediction of energy expenditure and physical activity in preschoolers. Med Sci Sports Exerc. 2014;46(6):1216-26.

7. Cain KL, Sallis JF, Conway TL, Van Dyck D, Calhoon L. Using accelerometers in youth physical activity studies: a review of methods. J Phys Act Health. 2012;10(3):437-50.

8. Carson V, Ridgers ND, Howard BJ, et al. Light-intensity physical activity and cardiometabolic biomarkers in US adolescents. PLoS One. 2013;8(8):e71417.

9. Cole TJ, Freeman JV, Preece MA. Body mass index reference curves for the UK, 1990. Arch Dis Child. 1995;73(1):25-9. 
10. Collings PJ, Brage S, Ridgway CL, et al. Physical activity intensity, sedentary time, and body composition in preschoolers. Am J Clin Nutr. 2013;97(5):1020-8.

11. Collings PJ, Westgate K, Vaisto J, et al. Cross-sectional associations of objectively-measured physical activity and sedentary time with body composition and cardiorespiratory fitness in mid-childhood: the PANIC study. Sports Med. 2017;47(4):769-80.

12. Collings PJ, Wijndaele K, Corder K, et al. Prospective associations between sedentary time, sleep duration and adiposity in adolescents. Sleep Med. 2015;16(6):717-22.

13. Costa S, Barber SE, Cameron N, Clemes SA. The objective measurement of physical activity and sedentary behaviour in 2-3 year olds and their parents: a cross-sectional feasibility study in the biethnic Born in Bradford cohort. BMC Public Health. 2015;15:1109.

14. Department for Communities and Local Government. The English Index of Multiple Deprivation 2015: Guidance. Department for Communities and Local Government; 2015.

15. Department of Health. Start Active, Stay Active: A Report on Physical Activity from the Four Home Countries' Chief Medical Officers. London: Department of Health; 2011.

16. Department of Healthy Ageing. National Physical Activity Recommendations for Children 0-5 Years. Commonwealth of Australia; 2010.

17. Ekelund U, Hildebrand M, Collings PJ. Physical activity, sedentary time and adiposity during the first two decades of life. Proc Nutr Soc. 2014;73(2):319-29.

18. Ekelund U, Sardinha LB, Anderssen SA, et al. Associations between objectively assessed physical activity and indicators of body fatness in 9- to 10-y-old European children: a population-based study from 4 distinct regions in Europe (the European Youth Heart Study). Am J Clin Nutr. 2004;80(3):584-90.

19. Fees BS, Fischer E, Haar S, Crowe LK. Toddler activity intensity during indoor free-play: stand and watch. J Nutr Educ Behav. 2015;47(2):170-5.

20. Gillis L, Tomkinson G, Olds T, et al. Research priorities for child and adolescent physical activity and sedentary behaviours: an international perspective using a twin-panel Delphi procedure. Int $J$ Behav Nutr Phys Act. 2013;10(1):112.

21. Griffiths LJ, Sera F, Cortina-Borja M, Law C, Ness A, Dezateux C. Objectively measured physical activity and sedentary time: crosssectional and prospective associations with adiposity in the Millennium Cohort Study. BMJ Open. 2016;6(4):e010366.

22. Hay J, Maximova K, Durksen A, et al. Physical activity intensity and cardiometabolic risk in youth. Arch Pediatr Adolesc Med. 2012;166(11):1022-9.

23. Hesketh KR, McMinn AM, Ekelund U, et al. Objectively measured physical activity in four-year-old British children: a crosssectional analysis of activity patterns segmented across the day. Int J Behav Nutr Phys Act. 2014;11:1.

24. Howie EK, Brown WH, Dowda M, McIver KL, Pate RR. Physical activity behaviours of highly active preschoolers. Pediatr Obes. 2013;8(2):142-9.

25. Janz KF, Levy SM, Burns TL, Torner JC, Willing MC, Warren J. Fatness, physical activity, and television viewing in children during the adiposity rebound period: the Iowa Bone Development Study. Prev Med. 2002;35(6):563-71.

26. Katzmarzyk PT. Physical activity, sedentary behavior, and health: paradigm paralysis or paradigm shift? Diabetes. 2010;59(11): 2717-25.

27. Kohl HW, Fulton JE, Caspersen CJ. Assessment of physical activity among children and adolescents: a review and synthesis. Prev Med. 2000;31(2):S54-76.

28. Kwon S, Janz KF, Burns TL, Levy SM. Association between lightintensity physical activity and adiposity in childhood. Pediatr Exerc Sci. 2011;23(2):218-29.

29. Leppänen $M H$, Nyström CD, Henriksson P, et al. Physical activity intensity, sedentary behavior, body composition and physical fitness in 4-year-old children: results from the MINISTOP trial. Int $J$ Obes (Lond). 2016;40(7):1126-33.

30. McEachan RRC, Santorelli G, Bryant M, et al. The HAPPY (Healthy and Active Parenting Programmme for early Years) feasibility randomised control trial: acceptability and feasibility of an intervention to reduce infant obesity. BMC Public Health. 2016;16(1):211.

31. Mekary RA, Willett WC, Hu FB, Ding EL. Isotemporal substitution paradigm for physical activity epidemiology and weight change. Am J Epidemiol. 2009;170(4):519-27.

32. Metallinos-Katsaras ES, Freedson PS, Fulton JE, Sherry B. The association between an objective measure of physical activity and weight status in preschoolers. Obesity. 2007;15(3):686-94.

33. Owen CG, Nightingale CM, Rudnicka AR, et al. Physical activity, obesity and cardiometabolic risk factors in 9- to 10-year-old UK children of White European, South Asian and Black AfricanCaribbean origin: the Child Heart and health Study in England (CHASE). Diabetologia. 2010;53(8):1620-30.

34. Perini TA, de Oliveira GL, Ornelia JS, de Oliveira FP. Technical error of measurement in anthropometry. Rev Bras Med Esporte. 2005;11:81-5.

35. Riddoch CJ, Leary SD, Ness AR, et al. Prospective associations between objective measures of physical activity and fat mass in 12-14 year old children: the Avon Longitudinal Study of Parents and Children (ALSPAC). BMJ. 2009;339:b4544.

36. Timmons BW, Leblanc AG, Carson V, et al. Systematic review of physical activity and health in the early years (aged 0-4 years). Appl Physiol Nutr Metab. 2012;37(4):773-92.

37. Tremblay MS, LeBlanc AG, Carson V, et al. Canadian physical activity guidelines for the early years (aged $0-4$ years). Appl Physiol Nutr Metab. 2012;37(2):345-69.

38. Vale SM, Santos RM, da Cruz Soares-Miranda LM, Moreira CM, Ruiz JR, Mota JA. Objectively measured physical activity and body mass index in preschool children. Int J Pediatr. 2010;2010: 479439.

39. White J, Jago R. Prospective associations between physical activity and obesity among adolescent girls: racial differences and implications for prevention. Arch Pediatr Adolesc Med. 2012;166(6): $522-7$.

40. Wright J, Small N, Raynor P, et al. Cohort profile: the Born in Bradford multi-ethnic family cohort study. Int $J$ Epidemiol. 2013;42(4):978-91. 